\title{
Study on the Joining of Titanium and Aluminum Dissimilar Alloys by Friction Stir Welding
}

\author{
Yuhua Chen ${ }^{*}, 1$ Changhua $\mathrm{Liu}^{2}$ and Geping Liu ${ }^{1}$ \\ ${ }^{I}$ National Defense Key Disciplines Laboratory of Light Alloy Processing Science and Technology, Nanchang Hangkong \\ University, Nanchang 330063, China \\ ${ }^{2}$ College of Mechanical and Materials Engineering, Jiujiang University, Jiujiang 332005, China
}

\begin{abstract}
Titanium alloy TC1 and Aluminum alloy LF6 were butt jointed and lap jointed by friction stir welding (FSW), and the influence of process parameters on formation of weld surface, cross-section morphology and strength were studied. The results show that, Titanium and Aluminum dissimilar alloy is difficult to be butt joined by FSW, and some defects such as cracks and grooves are easy to occur. When the tool rotation rate is $950 \mathrm{r} / \mathrm{min}$ and the welding speed is $118 \mathrm{~mm} / \mathrm{min}$, the tensile strength of the butt joint is $131 \mathrm{MPa}$ which is the highest. FSW is suitable for lap joining of TC1 Titanium alloy and LF6 Aluminum alloy dissimilar materials, an excellent surface appearance is easy to obtain, but the shear strength of the lap welding joint is not high. At the welding speed of $60 \mathrm{~mm} / \mathrm{min}$ and the tool rotation rate of 1500 $\mathrm{r} / \mathrm{min}$, the lap joint has the largest shear strength of $48 \mathrm{MPa}$. At the welding speed of $150 \mathrm{~mm} / \mathrm{min}$ and the tool rotation rate of $1500 \mathrm{r} / \mathrm{min}$, crack like a groove occurs on the interface and the shear strength is zero.
\end{abstract}

Keywords: Joining of Ti/Al dissimilar alloys, friction stir welding, butt welding, lap welding.

\section{INTRODUCTION}

Aluminum alloys are widely used in automotive, aerospace and ship industries as high strength-to-weight ratio materials. Titanium alloys are also attractive in these fields due to their lower density, high specific strength and excellent corrosion-resistance. With the increasing demand for lightweight components, their application is becoming more extensive [1-3]. In some special locations, the complementary characteristics of $\mathrm{Ti}$ and $\mathrm{Al}$ are required, such as increased strength, lowered weight and cost. Therefore, the joining of Al alloys and $\mathrm{Ti}$ alloys is an emergent problem to be solved in industrial application. However, it is sufficiently difficult to obtain sound dissimilar welds of these two kinds of alloys because of the great differences in their performance, including crystal microstructure, melting point, heat conductivity and coefficient of linear expansion, etc. [4,5]. Using traditional fusion welding method, Al element is severely lost at the temperature below the melting point of Ti. Composition of the weld metal is asymmetric and the laminated Ti/Al intermatellics such as $\mathrm{Ti}_{3} \mathrm{Al}$, TiAl and TiAl3 can be easily formed. So it is difficult to weld the Ti/Al compound structure by means of fusion welding [6].

To solve this problem, special welding methods have been reported for joining these two materials such as pressure welding [7], diffusion bonding [8,9], vacuum brazing [10], laser welding-brazing [11,12], liquid phase diffusion welding [13] and friction welding [14]. These studies showed that the key issue encountered in welding Al

*Address correspondence to this author at the School of Aeronautical Manufacturing Engineering, Nanchang Hangkong University, Nanchang 330063, China; Tel: +86-791-3863023; Fax: +86-791-3953312;

E-mail: ch.yu.hu@163.com alloy to Ti alloys is the formation of interfacial intermetallic phases [15], which depends on the process related temperature-time cycles. Friction stir welding (FSW), a solid-state welding process patented by The Welding Institute (TWI) in 1991, is a potential candidate for the joining of dissimilar materials due to its advantageous lower processing temperature over conventional fusion welding [16]. There are several studies on the FSW of Ti/Al dissimilar alloys at present in the world. Dressler [17] joined titanium alloy TiAl6V4 and aluminium alloy 2024-T3 successfully and investigated microstructure, hardness and tensile strength of the butt joint. It was found the ultimate tensile strength of the joint can reach $73 \%$ of $2024-\mathrm{T} 3$ base material strength. Chen [18] studied lap joining of Al-Si alloy and pure titanium by FSW and the maximum failure load of joints reached $62 \%$ of Al-Si alloy base metal with the joints fractured at the interface.

In this paper, dissimilar metals of $\mathrm{Ti}$ alloy $\mathrm{TC} 1$ and $\mathrm{Al}$ alloy LF6 were butt jointed and lap jointed by FSW and and the influence of process parameters on formation of weld surface, morphology of weld cross- section and tensile strength were studied in order to provide the theoretical guidance for obtaining an optimal process parameters and improved mechanical properties of the welded joint.

\section{EXPERIMENTAL}

TC1 Ti alloy and LF6 Al alloy plates with thickness of 2 $\mathrm{mm}$ were used in the present study, and the chemical compositions and mechanical properties are separately listed in Tables $\mathbf{1}$ and $\mathbf{2}$. The plates are cut and machined into rectangular welding samples, which is $250 \mathrm{~mm}$ long and 100 $\mathrm{mm}$ wide. The surfaces of the welding samples were ground with grit paper to remove the oxide film and then cleaned by ethanol before welding. The welding tests are carried out on the homemade clamp using friction stir welding machine 
which is modified from milling machine, the tool rotation rate changes from $600 \mathrm{r} / \mathrm{min}$ to $1180 \mathrm{r} / \mathrm{min}$, welding speed changes from $95 \mathrm{~mm} / \mathrm{min}$ to $190 \mathrm{~mm} / \mathrm{min}$, the tilt angle of the stir head is $2^{\circ}$.

Table 1. Composition and Mechanical Property of LF6

\begin{tabular}{|c|c|c|c|c|c|c|c|}
\hline \multicolumn{5}{|c|}{ Composition (Wt\%) } & \multicolumn{2}{|c|}{ Mechanical property } \\
\hline $\mathbf{M n}$ & $\mathbf{M g}$ & $\mathbf{S i}$ & $\mathbf{C u}$ & $\mathbf{F e}$ & $\mathbf{Z n}$ & $\boldsymbol{\sigma b}(\mathbf{M P a})$ & $\boldsymbol{\delta}(\%)$ \\
\hline \hline 0.6 & 5.8 & 0.3 & 0.1 & 0.3 & 0.15 & 320 & 15 \\
\hline
\end{tabular}

Table 2. Composition and Mechanical Property of TC1

\begin{tabular}{|c|c|c|c|c|c|c|c|c|}
\hline \multicolumn{7}{|c|}{ Composition (Wt\%) } & \multicolumn{2}{|c|}{ Mechanical Property } \\
\hline Al & $\mathbf{M n}$ & $\mathbf{F e}$ & $\mathbf{S i}$ & $\mathbf{C}$ & $\mathbf{O}$ & $\mathbf{N}$ & $\boldsymbol{\sigma b}(\mathbf{M P a})$ & $\boldsymbol{\delta}(\%)$ \\
\hline \hline 2.0 & 1.8 & 0.1 & 0.15 & 0.1 & 0.15 & 0.05 & 650 & 20 \\
\hline
\end{tabular}

During butt welding, titanium alloy is placed on the advancing side, aluminum alloy is placed on the retreating side, the offset of the pin which is the distance of the edge of the pin and the seam of titanium and aluminum alloy is 0.5 $\mathrm{mm}$. A tool with a concaved shoulder of $15 \mathrm{~mm}$ in diameter and a cone-threaded pin of $5 \mathrm{~mm}$ in diameter and $1.85 \mathrm{~mm}$ in length was used. During lap welding, LF6 Al alloy and TC1 Ti alloy were placed at the advancing side (AS) and the retreating side (RS) of the tool pin, the aluminum alloy plate is placed over the titanium plate (see Fig. 1). A tool with a concaved shoulder of $15 \mathrm{~mm}$ in diameter and a conethreaded pin of $4 \mathrm{~mm}$ in diameter and $2.1 \mathrm{~mm}$ in length was used.

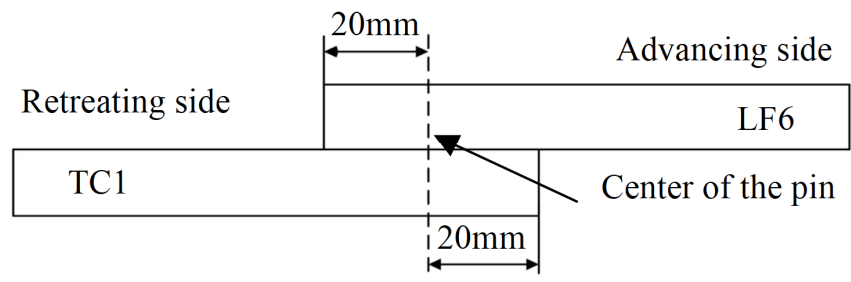

Fig. (1). Sketch map of relative position between $\mathrm{Ti}$ alloy and $\mathrm{Al}$ alloy of lap welding.

Microstructure and interface characteristic analysis were performed on the cross section perpendicular to the welding direction. A solution of $2 \mathrm{~mL} \mathrm{HF}$ acid, $4 \mathrm{~mL} \mathrm{HNO}_{3}$ acid and $94 \mathrm{~mL}$ distilled water was used as the etchant of the specimen. Microstructure and element distribution of the weld were observed by optical microscope (OM, 4XB-TV) and scanning electron microscope (SEM, Quata200) equipped with an energy dispersive X-ray spectroscopy (EDS) system. The mechanical properties of the joint are measured by tensile tests which are carried out at room temperature at a crosshead speed of $3 \mathrm{~mm} / \mathrm{min}$ using a tensile testing machine. The tensile strength of the butt joints and shear strength of the lap joints are evaluated using three tensile specimens cut from the same joint on electronic almighty testing machine (WDW-50) which is controlled by computer. The shape of the test specimen is rectangular and the width of each specimen is $12.5 \mathrm{~mm}$.

\section{RESULTS AND DISCUSSION}

\subsection{Influence of Process Parameters on Morphology of Surface and Cross Section of Butt Joints}

When the tool rotation rate (n) is $1180 \mathrm{r} / \mathrm{min}$, and welding speed (v) changes from $95 \mathrm{~mm} / \mathrm{min}$ to $190 \mathrm{~mm} / \mathrm{min}$, the longitudinal cracks always occur at the side of titanium alloy after welding, as shown in Fig. (2). For the FSW of titanium/aluminum dissimilar materials, the reasons of generating cracks is related to the intermetallic compound formed in the weld. $\mathrm{Ti}$ and $\mathrm{Al}$ are active element, according to Ti-A1 duality phase diagram, $\mathrm{Ti}$ and $\mathrm{Al}$ can form TiAl, $\mathrm{Ti}_{3} \mathrm{Al}, \mathrm{Al}_{3} \mathrm{Ti}$ and other intermetallic compounds. During FSW, the frictional heat between the stir head and workpiece make the weld temperature rise, at the same time, Ti and $\mathrm{Al}$ element in the weld zone are mixed under the action of the stir head and experience severe plastic deformation, combination of both make $\mathrm{Ti}$ and $\mathrm{Al}$ form Ti-Al intermetallic compounds at solid state. A large number of brittle intermetallic compounds makes the weld brittle, the weld crazes under the action of welding stress at last. The higher the rotation speed is, the more frictional heat between the stir head and workpiece generates, more intermetallic compounds form in the weld, and greater possibility the weld crazes. So the weld crazes easily at the tool rotation rate of $1180 \mathrm{r} / \mathrm{min}$.

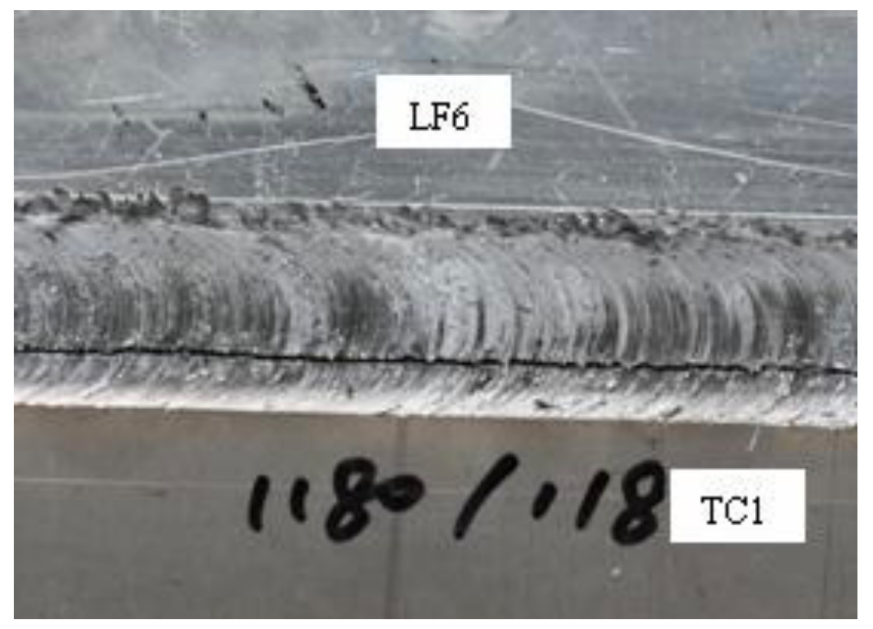

Fig. (2). Surface morphology of butt joint of 1180r/min.

When the tool rotation rate reduces to $600 \mathrm{r} / \mathrm{min}$, and welding speed changes in the range of $95 \mathrm{~mm} / \mathrm{min}$ and 190 $\mathrm{mm} / \mathrm{min}$, the formation of weld surface is rough, both sides of the weld have more excessive flash, and grooves occur in the weld, as shown in Fig. (3). The reason is that, too low rotation speed results in less heat generated by friction in per unit length of the weld, the temperature of weld zone is too low, A1/Ti can't be jointed in plastic state, and the macrodefect like groove in the weld occurs.

A large number of technological experimentions show that, when rotation speed is $750 \mathrm{r} / \mathrm{min}$ and $950 \mathrm{r} / \mathrm{min}$, the welding speed is $118 \mathrm{~mm} / \mathrm{min}$ and $150 \mathrm{~mm} / \mathrm{min}$, a good formation of weld surface can be obtained, as shown in Figs. $(4,5)$. When the welding speed increases to $190 \mathrm{~mm} / \mathrm{min}$, the grooves appear in the weld for the heat is not enough as well.

Metallographic specimens were intercepted on the weld sample at the tool rotation rate of $750 \mathrm{r} / \mathrm{min}$ and $950 \mathrm{r} / \mathrm{min}$, 


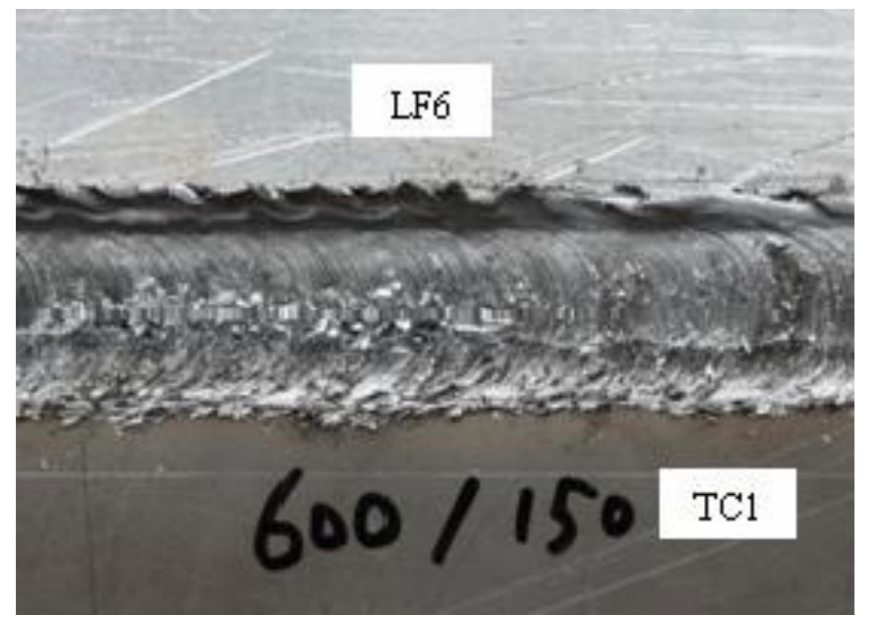

Fig. (3). Surface morphology of butt joint of $600 \mathrm{r} / \mathrm{min}$.
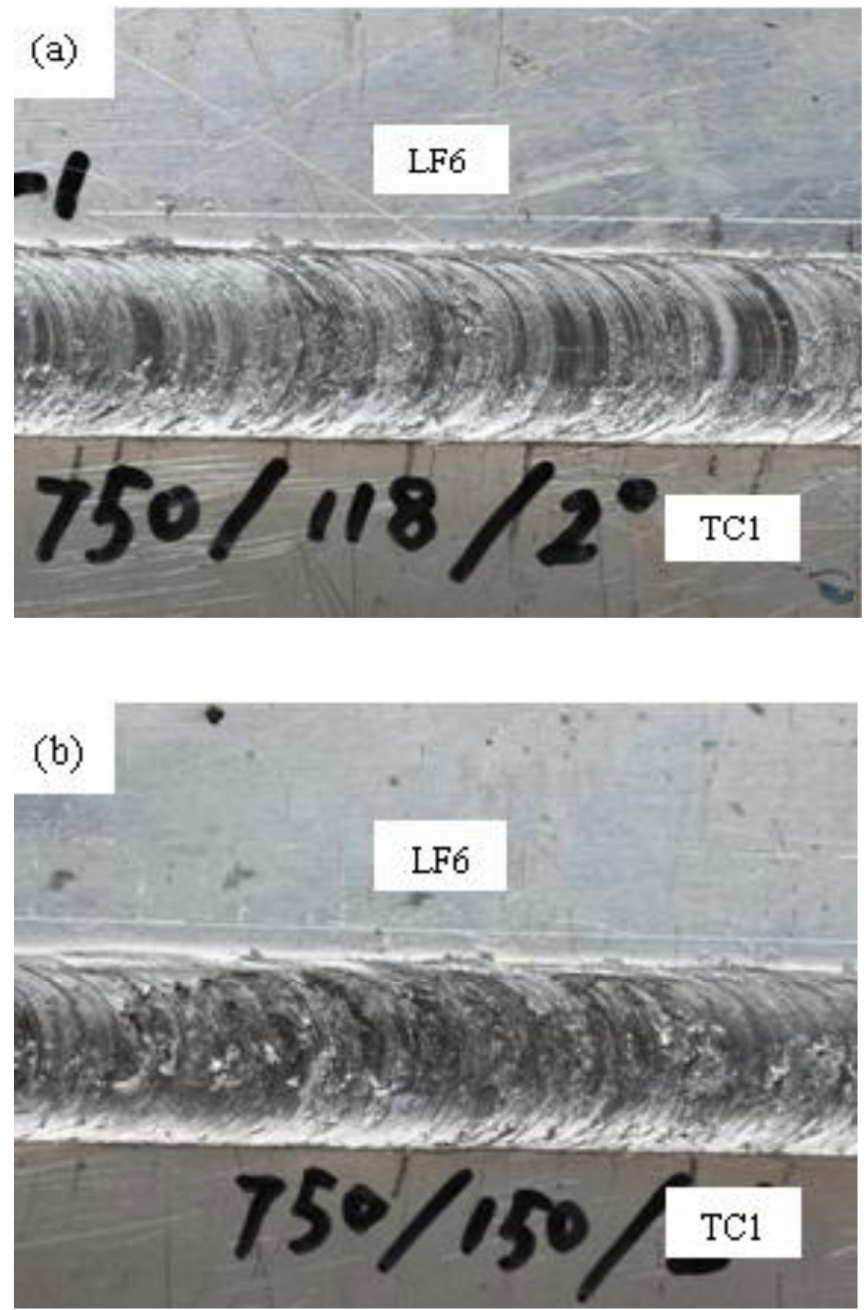

Fig. (4). Surface morphology of butt joint of 750r/min: (a) $\mathrm{v}=118 \mathrm{~mm} / \mathrm{min} ;(\mathbf{b}) \mathrm{v}=150 \mathrm{~mm} / \mathrm{min}$.

welding speed of $118 \mathrm{~mm} / \mathrm{min}$ and $150 \mathrm{~mm} / \mathrm{min}$, then observe the morphology of cross-section of welded joint, as shown in Fig. (6). We can see from the figure, when the tool rotation rate is $750 \mathrm{r} / \mathrm{min}$ and welding speed is $118 \mathrm{~mm} / \mathrm{min}$ (Fig. 6a), there is a part of titanium in the weld zone, but the titanium/aluminum interface is clear and perpendicular to the surface of the base material. It indicates that titanium and aluminum alloy don't sufficiently stir and mix during FSW. When the welding speed increase to $150 \mathrm{~mm} / \mathrm{min}$ (Fig. 6b), the cracks will appear at the titanium/aluminum interface below the shoulder. When the tool rotation rate is $950 \mathrm{r} / \mathrm{min}$ and the welding speed is $118 \mathrm{~mm} / \mathrm{min}$ (Fig. 6c), interface bonding of titanium and aluminum in the cross-section of weld joint is well and only a little of titanium transfer into the weld. When the welding speed increase to $150 \mathrm{~mm} / \mathrm{min}$ (Fig. 6d), there is a lot of titanium near by the titanium alloy base metal, as a result, more titanium/aluminum intermetallic compounds was created in the weld, it will decreases the tensile strength.
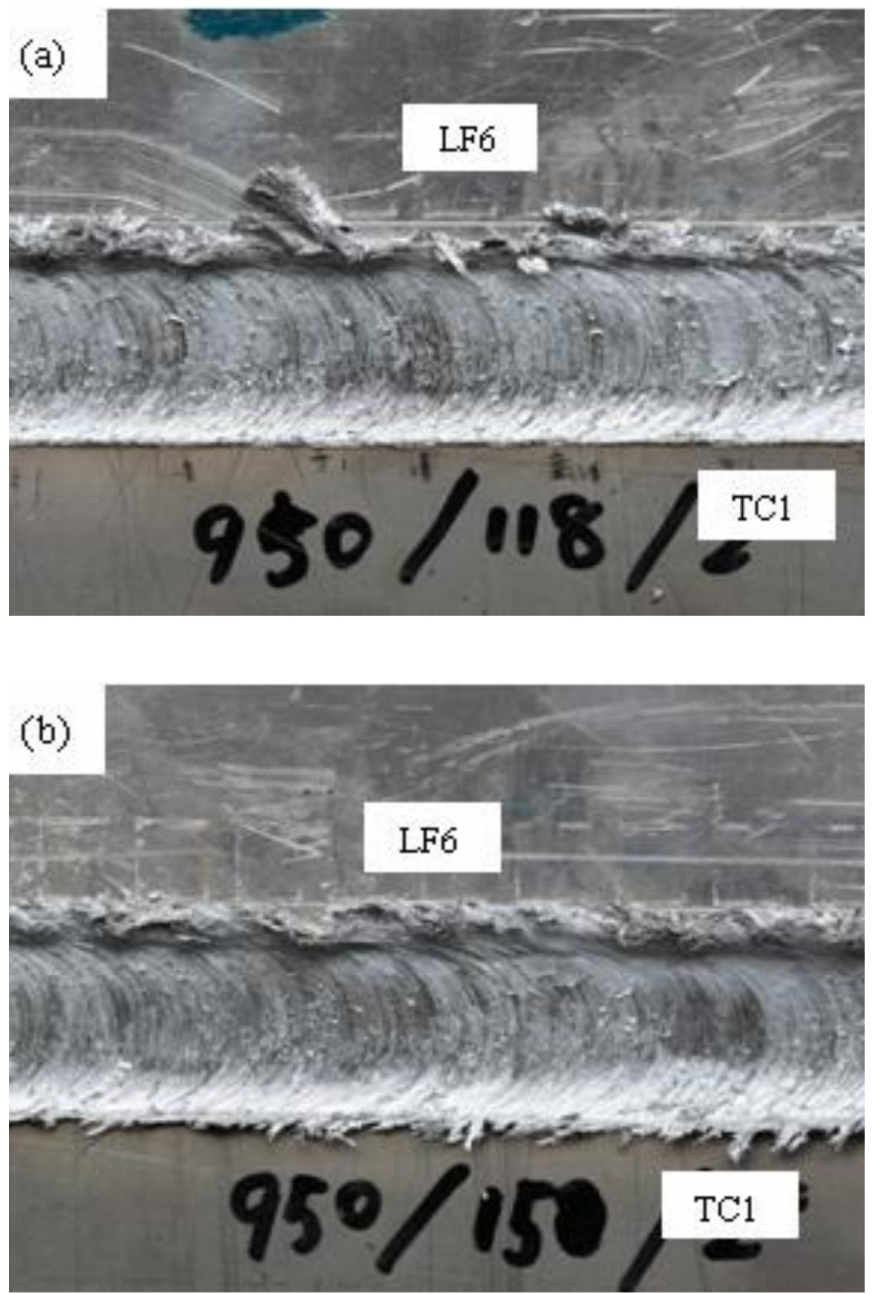

Fig. (5). Surface morphology of butt joint of 950r/min: (a) $\mathrm{v}=118 \mathrm{~mm} / \mathrm{min} ;(\mathbf{b}) \mathrm{v}=150 \mathrm{~mm} / \mathrm{min}$.

\subsection{Tensile Strength of the Butt Welding Joints}

The weld joints of four group parameters (the tool rotation rate is $750 \mathrm{r} / \mathrm{min}$ or $900 \mathrm{r} / \mathrm{min}$, welding speed is 118 $\mathrm{mm} / \mathrm{min}$ or $150 \mathrm{~mm} / \mathrm{min}$ ) were made into standard tensile specimens, then the strength of these weld joints were tested. Three tensile specimens were cut from each parameter and the average of the strength of the three specimens was regard as the tensile strength of weld joints, the results are seen in Table 3. 

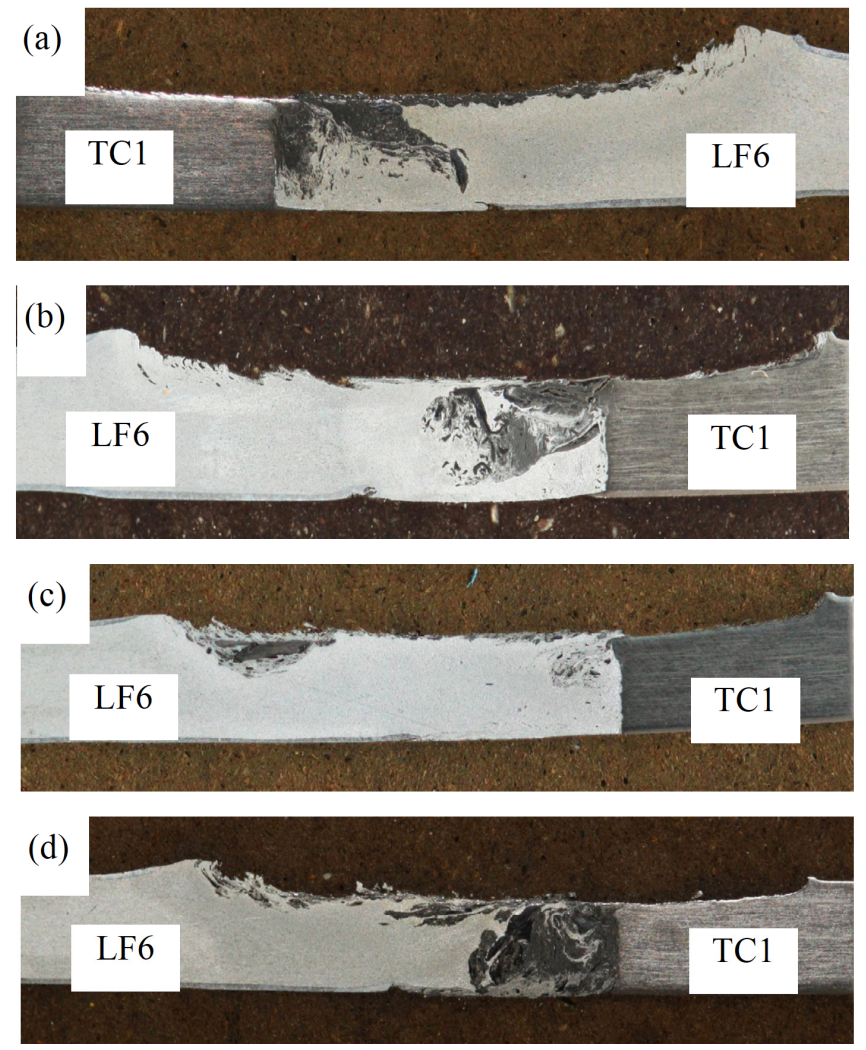

Fig. (6). The macroscopic morphology of cross section of butt joint: (a) $\mathrm{n}=750 \mathrm{r} / \mathrm{min}, \mathrm{v}=118 \mathrm{~mm} / \mathrm{min}$; (b) $\mathrm{n}=750 \mathrm{r} / \mathrm{min}, \mathrm{v}=150 \mathrm{~mm} / \mathrm{min}$; (c) $\mathrm{n}=950 \mathrm{r} / \mathrm{min}, \mathrm{v}=118 \mathrm{~mm} / \mathrm{min}$; (d) $\mathrm{n}=950 \mathrm{r} / \mathrm{min}, \mathrm{v}=150 \mathrm{~mm} / \mathrm{min}$.

Table 3. Tensile Strength of Butt Joint Ti/Al Alloy Dissimilar Materials

\begin{tabular}{|c|c|c|c|}
\hline $\begin{array}{c}\text { Sample } \\
\text { Number }\end{array}$ & $\begin{array}{c}\text { Rotational Speed } \\
(\mathbf{r} / \mathbf{m i n})\end{array}$ & $\begin{array}{c}\text { Welding Speed } \\
(\mathbf{m m} / \mathbf{m i n})\end{array}$ & $\begin{array}{c}\text { Average Tensile } \\
\text { Strength (MPa) }\end{array}$ \\
\hline \hline 1 & 750 & 118 & - \\
\hline 2 & 750 & 150 & 16.4 \\
\hline 3 & 950 & 118 & 131.1 \\
\hline 4 & 950 & 150 & 96.4 \\
\hline
\end{tabular}

It can be seen from Table 3 that the tensile strength is the lowest when the tool rotation rate is $750 \mathrm{r} / \mathrm{min}$ and welding speed is $118 \mathrm{~mm} / \mathrm{min}$, two specimens fractured when they were clamped in the tensile testing machine, indicating that Titanium/aluminum combine badly at these parameters, it is consistent with the morphology observed from weld crosssection. When rotational speed is $950 \mathrm{r} / \mathrm{min}$ and welding speed is $118 \mathrm{~mm} / \mathrm{min}$, the strength of joint is is $131 \mathrm{MPa}$ which is the highest, but it is still far below the strength $(314 \mathrm{MPa})$ of LF6 aluminum alloy base material and the strength $(600 \mathrm{MPa})$ of TC1 titanium alloy base material. So about the FSW of Titanium and Aluminum dissimilar materials, further measures (such as the design of stir head, add the middle materials etc.) are took to improve the strength of joint and then it is possible to carry out the applications of engineering.

\subsection{Surface and Cross Section of Lap Joints at Different Parameters}

The friction stir welded Ti/Al lap joints at the parameters listed in Table $\mathbf{4}$ all have an excellent surface appearance, a typical surface appearance as seen in Fig. (7). It can be seen from Fig. (7) that the surface is smooth and without any defects. But the interface macrograph of the lap joint crosssection at different parameters has very difference as shown in Fig. (8). It can be seen from Fig. (8) that, at the welding speed of $60 \mathrm{~mm} / \mathrm{min}$ and the tool rotation rate of $1500 \mathrm{r} / \mathrm{min}$, the stir zone (SZ) of weld contains a large amount of $\mathrm{Ti}$ particles and the cross-section morphology of the lap joint is good (see Fig. 8a). The SZ reveals a mixture of $\mathrm{f}$ Al alloy and titanium pushed away from the titanium surface by the stirring action of the tool pin. When the welding speed increases to $95 \mathrm{~mm} / \mathrm{min}$ and $118 \mathrm{~mm} / \mathrm{min}$, the cross-section morphology is also good but the amount of Ti particles in the stir zone of weld decreases (see Fig. 8b). This may be because the welding heat input reduces and the plastic flow ability of Ti alloy decreases when the welding speed increases. When the welding speed increases to 150 $\mathrm{mm} / \mathrm{min}$, crack occurs on the interface between Ti alloy and Al alloy (see Fig. 8c). When the welding speed is 95 $\mathrm{mm} / \mathrm{min}$ and the tool rotation rate decrseas to $950 \mathrm{r} / \mathrm{min}$ and $600 \mathrm{r} / \mathrm{min}$, the tip of tool pin nearly does not touch the surface of lower Ti alloy plate because lower tool rotation rate effectively avoids serious softening of Al. It can be seen from Fig. (8d, e) that $\mathrm{Al}$ alloy and $\mathrm{Ti}$ alloy are joined tightly but there is little $\mathrm{Ti}$ in the $\mathrm{SZ}$.

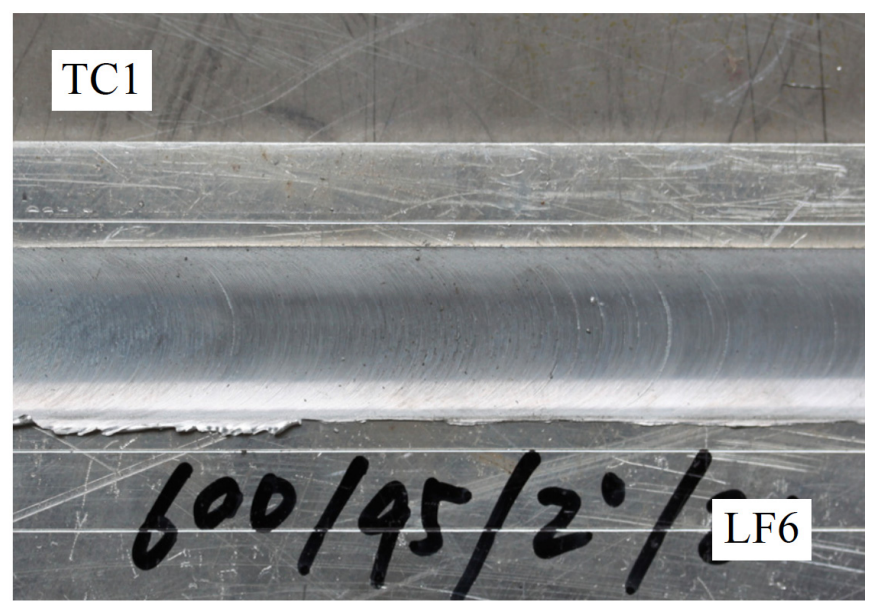

Fig. (7). Surface morphology of of Ti/Al dissimilar alloys lap joint.

Table 4. Lap Welding Parameters

\begin{tabular}{|c|c|c|c|c|c|c|}
\hline Weld Sample No. & 1 & 2 & 3 & 4 & 5 & 6 \\
\hline Tool Rotation Rate/n (r/min) & 1500 & 1500 & 1500 & 1500 & 950 & 600 \\
\hline Welding Speed/v (mm/min) & 60 & 95 & 118 & 150 & 95 & 95 \\
\hline
\end{tabular}

\subsection{Shear Strength of the Lap Welding Joints}

Table 5 shows the shear strength of the lap joints welded at parameters listed in Table $\mathbf{4}$. It can be seen from Table $\mathbf{5}$ that the shear strength decreases with the increasing of the welding speed when the tool rotation rate is fixed at 1500 

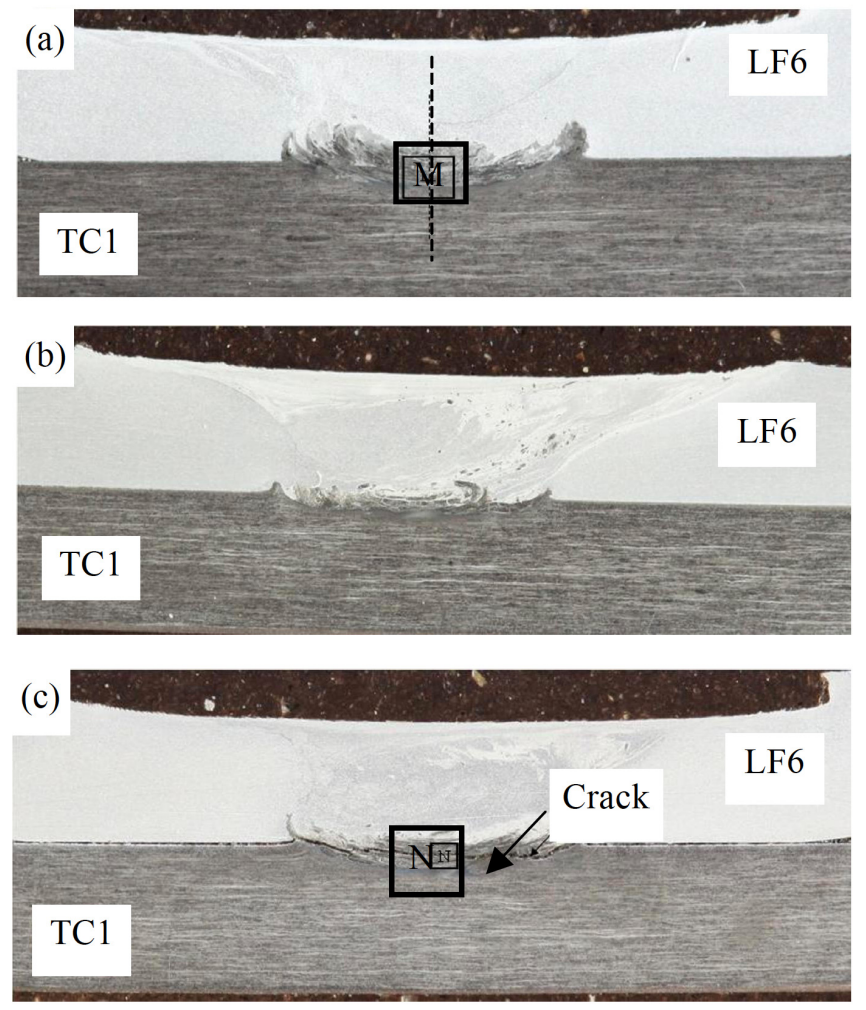

(d)

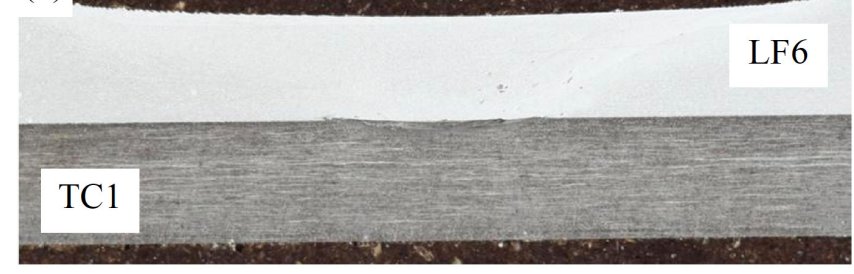

(e)

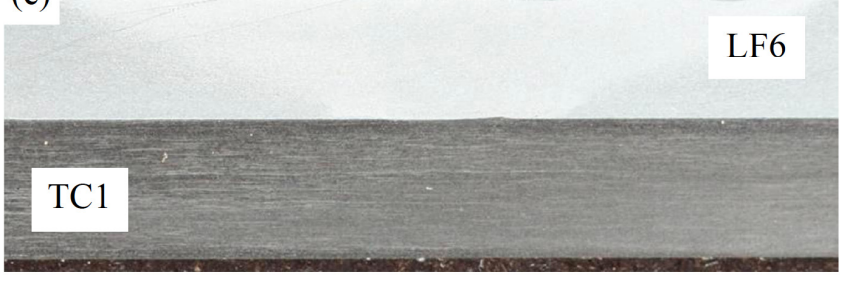

Fig. (8). The macroscopic morphology of cross section of lap joint of Ti/Al dissimilar alloys: (a) $\mathrm{n}=1500 \mathrm{r} / \mathrm{min}, \mathrm{v}=60 \mathrm{~mm} / \mathrm{min}$; (b) $\mathrm{n}=1500 \mathrm{r} / \mathrm{min}, \mathrm{v}=118 \mathrm{~mm} / \mathrm{min}$; (c) $\mathrm{n}=1500 \mathrm{r} / \mathrm{min}, \mathrm{v}=150 \mathrm{~mm} / \mathrm{min}$; (d) $\mathrm{n}=950 \mathrm{r} / \mathrm{min}, \mathrm{v}=95 \mathrm{~mm} / \mathrm{min}$; (e) $\mathrm{n}=600 \mathrm{r} / \mathrm{min}, \mathrm{v}=95 \mathrm{~mm} / \mathrm{min}$.

$\mathrm{r} / \mathrm{min}$. The shear strength of the joint welded at the tool rotation rate of $1500 \mathrm{r} / \mathrm{min}$ and welding speed of $150 \mathrm{~mm} / \mathrm{min}$ is zero which has crack on the interface. When the welding speed is $95 \mathrm{~mm} / \mathrm{min}$ and the tool rotation rates are $950 \mathrm{r} / \mathrm{min}$ and $600 \mathrm{r} / \mathrm{min}$, the shear strength of the welded joints are relatively larger than the joint welded at the tool rotation rate of $1500 \mathrm{r} / \mathrm{min}$ and welding speed of $95 \mathrm{~mm} / \mathrm{min}$. This may be because there is less amount of intermetallic compound on the interface between $\mathrm{Al}$ alloy and $\mathrm{Ti}$ alloy since there is little Ti in the SZ (see Fig. 8d, e).
Table 5. Shear Strength of the Lap Joints

\begin{tabular}{|c|c|c|c|c|c|c|}
\hline Weld Sample No. & 1 & 2 & 3 & 4 & 5 & 6 \\
\hline Tool Rotation Rate/n (r/min) & 1500 & 1500 & 1500 & 1500 & 950 & 600 \\
\hline Welding Speed/v (mm/min) & 60 & 95 & 118 & 150 & 95 & 95 \\
\hline Shear strength/P (MPa) & 48 & 36 & 32 & 0 & 41 & 44 \\
\hline
\end{tabular}

\section{CONCLUSIONS}

(1) Weld surface of friction stir welded butt joint of Titanium and Aluminum dissimilar metals easily appears longitudinal cracks if the tool rotation rate of stir head is too high, the weld surface is rough and occurs grooves if the tool rotation rate of stir head is too low.

(2) When the tool rotation rate is $750 \mathrm{r} / \mathrm{min}$ and $950 \mathrm{r} / \mathrm{min}$, the welding speed is $118 \mathrm{~mm} / \mathrm{min}$ and $150 \mathrm{~mm} / \mathrm{min}$, a good formation of butt weld surface can be obtained. When the tool rotation rate is $750 \mathrm{r} / \mathrm{min}$, the welding speed is $118 \mathrm{~mm} / \mathrm{min}$ and $150 \mathrm{~mm} / \mathrm{min}$, the interface bonding of titanium and aluminum in the weld crosssection of butt joint is bad which results in a low strength joint.

(3) When the tool rotation rate is $950 \mathrm{r} / \mathrm{min}$ and welding speed is $118 \mathrm{~mm} / \mathrm{min}$, the strength of the butt joint of Titanium and Aluminum dissimilar metals is $131 \mathrm{MPa}$ which is the highest.

(4) FSW is suitable for lap joining of TC1 Ti alloy and LF6 Al alloy dissimilar materials, an excellent surface appearance is easy to obtain. But the interface macrograph of the lap joint cross-section at different parameters has very difference. When the welding speed increases or the tool rotation rate decrseas, the amount of Ti particles which is stirred into the stir zone by the forcr of tool pin decreases. When the welding speed increases to $150 \mathrm{~mm} / \mathrm{min}$ crack like a groove occurs on the interface.

(5) The shear strength of the lap joints decreases with the increasing of the welding speed. In this paper, the shear strength of the joint welded at the tool rotation rate of $1500 \mathrm{r} / \mathrm{min}$ and welding speed of $60 \mathrm{~mm} / \mathrm{min}$ is the largest of $48 \mathrm{MPa}$ and that of the joint at the tool rotation rate of $1500 \mathrm{r} / \mathrm{min}$ and welding speed of $150 \mathrm{~mm} / \mathrm{min}$ is zero.

\section{ACKNOWLEDGMENTS}

This work was supported by the Aviation Science Funds of China under grant No. 2009ZE56011.

\section{CONFLICT OF INTEREST}

All authors do not have conflicts of interest to declare.

\section{REFERENCES}

[1] Eylon D, Seagle SR. Titanium technology in the USA-an overview. J Mater Sci Technol 2001; 17: 439-43.

[2] Minggao Y, Xueren W, Zhishou Z. The Development Status and Prospects of Aeronautical Materials Technology. Aeronaut Manuf Technol 2003; 30:19-25. 
[3] Sohn HW, Bong HH, Hong SH. Microstructure and Bonding Mechanism of $\mathrm{Al} / \mathrm{Ti}$ Bonded Joint Using Al-10Si-1Mg Filler Metal. Mater Sci Eng 2003; 355: 231-40.

[4] Wilden J, Bergmann JP. Manufacturing of Titanium/Aluminum and Titanium/Steel Joints by Means of Diffusion Welding. Weld Cutting 2004; 3: 285-90.

[5] Jiangwei R, Yajiang L, Tao F. Microstructure characteristics in the interface zone of Ti/Al diffusion bonding. Mater Lett 2002; 56: 647-52.

[6] Korenyuk YM. Interaction of liquid aluminium and solid titanium in fusion welding. Weld Prod 1975; 22: 3-5.

[7] Saprygin VD. Pressure welding of aluminium-steel and titaniumaluminium transition pieces for low-temperature service. Weld Prod1975; 22: 29-31.

[8] Wei Y, Aiping W, Guisheng Z. Structure and forming process of the Ti/Al diffusion bonding joints. Rare Met Mater Eng 2007; 36: 700-4.

[9] Lee TW, Kim IK, Lee CH. Growth behavior of intermetallic Compound Layer in Sandwich-type Ti/Al diffusion couples inserted with Al-Si-Mg alloy foil. J Mat Sci Lett 1999; 18: 1599602.

[10] Pengfei Z, Hui K. Study on vacuum brazing of dissimilar alloys of Al/Ti. J Mater Eng 2001; 21: 25-8.
[11] Shuhai C, Liqun L, Yanbin C. Formation mechanism of porosity in laser welding-brazing of $\mathrm{Ti} / \mathrm{Al}$ dissimilar alloys. Rare Met Mater Eng 2010; 39: 32-6.

[12] Jiaming N, Liqun L, Yanbin C. The characteristic of laser brazing joints of Al/Ti dissimilar alloy. Chinese J Nonferrous Met 2007; 17: $617-22$

[13] Guoqing X, Gang Z, Jitai N. Parameters of Al/Ti diffusion bonded. Welding 2000; 3: 21-4.

[14] Fuji A, Ikeuchi K, Sato YS, Kokawa H. Interlayer growth at interfaces of $\mathrm{Ti} / \mathrm{Al}-1 \% \mathrm{Mn}, \mathrm{Ti} / \mathrm{Al}-46 \% \mathrm{Mg}$ and $\mathrm{Ti} /$ pure $\mathrm{Al}$ friction weld joints by post-weld heat treatment. Sci Technol Weld Join 2004; 9: 507-12.

[15] Fuji A. In situ observation of interlayer growth during heat treatment of friction weld joint between pure titanium and pure aluminium. Sci Technol Weld Join 2002; 7: 413-6.

[16] Mishra RS, Ma ZY. Friction stir welding and processing. Mater Sci Eng R 2005; 50: 1-78.

[17] Ulrike D, Gerhard B, Ulises AM. Friction stir welding of titanium alloy TiAl6V4 to aluminium alloy AA2024-T3. Mater Sci Eng A 2009; 526: 113-7.

[18] Chen YC, Nakata K. Microstructural characterization and mechanical properties in friction stir welding of aluminum and titanium dissimilar alloys. Mater Design 2009; 30: 469-74.

(C) Chen et al.; Licensee Bentham Open.

This is an open access article licensed under the terms of the Creative Commons Attribution Non-Commercial License (http://creativecommons.org/licenses/by-nc/3.0/) which permits unrestricted, non-commercial use, distribution and reproduction in any medium, provided the work is properly cited. 